\title{
Continuous-flow analysis of ammonia in perchloric acid supernate of blood or plasma using an ammonia-selective electrode
}

\author{
G. C. MOSES, R. J. THIBERT, AND T. F. DRAISEY \\ From the Department of Chemistry, University of Windsor, Windsor, Ontario N9B 3P4 and the \\ Department of Biochemistry, Salvation Army Grace Hospital, Windsor, Ontario N9A 5C6, Canada
}

SUMMARY A simple automated method for the estimation of ammonia in perchloric acid supernate of blood or plasma using an ion-selective electrode (Orion Ammonia-selective electrode, Model 9510) is described. The reliability of the proposed method has been checked against an ion-exchange resin procedure, which has been chosen as a standard procedure. Regression equation and correlation coefficient for the proposed method are $y=0.7 x+10$ and 0.945 , respectively, as compared with the chosen standard method. Within-run and between-run precision are $2.1 \%$ and $3.5 \%$ respectively. The average percent recovery is $97.5 \%$ and a tentative range is $13-73 \mu \mathrm{g} / \mathrm{dl}(9-52$ $\mu \mathrm{mol} / \mathrm{l})$ ammonia nitrogen.

Currently, several methods are used in the clinical chemistry laboratory for the assay of blood or plasma ammonia. These can be classified into three basic groups: procedures involving $(a)$ diffusion of ammonia from an alkaline medium with subsequent trapping in acid (Conway and Cooke, 1939), (b) separation of ammonia from the sample by ionexchange resin, followed by colour development with ninhydrin (Nathan and Rodkey, 1957), the Berthelot reaction (Miller and Rice, 1963; Forman, 1964; Fenton and Williams, 1968; Kingsley and Tager, 1970; Travenol Laboratories, Inc.) or Nesslers reagents (Dienst, 1961; Hutchinson and Labby, 1962), and (c) direct enzymatic analysis in which the formation or disappearance of NADH is measured spectrophotometrically (Mondzac et al., 1965; Jacobs and Olthuis, 1973; Smith Kline Instruments Inc., 1975).

Most recently, a number of ion-selective electrode procedures have been developed for the determination of this analyte in whole blood or plasma (Orion Research; Park and Fenton, 1973). Generally, those methods are based on changes in the electrode potential (millivolts) as a function of ammonia concentration (more specifically, as a function of ammonia activity). A more detailed account of the principles involved in the potentiometric deter-

Received for publication 28 April 1978 mination of ammonia in biological samples can be found in the Instruction Manual (Ammonia-Selective Electrode, Model 95-10, Orion Research) and in the paper by Proelss and Wright (1973).

In this paper we report our experience with an automated electrode system developed for the quantification of ammonia in perchloric acid supernate of blood. An automated procedure for the potentiometric determination of ammonia on perchloric acid supernate has not been done before. Proelss and Wright (1973) have described a manual procedure while Park and Fenton (1973) have reported an automated method in which measurements have been made on plasma directly. The proposed procedure has two main advantages over the method of Park and Fenton (1973): (1) All possible interferences from nonspecific ammonia liberated from plasma proteins as a result of alkalinisation are removed by precipitation with perchloric acid. (2) Perchloric acid supernate can be kept at $0^{\circ} \mathrm{C}$ for up to two hours (Proelss and Wright, 1973) without any significant change in the ammonia content, that is, the analysis need not be performed immediately after separation of filtrate from residue.

\section{Material}

REAGENTS

All reagents were reagent grade. 
GLASSWARE

All glassware was scrupulously clean and rinsed in ammonia-free distilled water.

\section{SOLUTIONS}

All solutions were made up with deionised or ammonia-free distilled water and stored at room temperature. Standard solutions were kept at $4^{\circ} \mathrm{C}$ when not in use.

\section{DILUENT}

Anhydrous $\mathrm{Na}_{2} \mathrm{SO}_{4}, 35 \cdot 5 \mathrm{~g}$, was dissolved in approximately $200 \mathrm{ml}$ of water in a litre flask; $5.85 \mathrm{~g}$ of $\mathrm{NaCl}$ was added and the solution was made up to 1 litre with water. Before the diluent was used an aliquot of $\mathrm{NH}_{4} \mathrm{Cl}$ standard sufficient to give a final concentration of about $0.01 \mathrm{mM} \mathrm{NH}_{4} \mathrm{Cl}$ was added.

STOCK STANDARD $\left(0 \cdot 1 \mathrm{M} \mathrm{NH}_{4} \mathrm{Cl}\right)$

Ammonia chloride, $0.535 \mathrm{~g}$, was dissolved in $50 \mathrm{ml}$ of water in a 100-ml graduated flask and made up to the mark with water.

\section{WORKING STANDARDS}

Serial dilutions of the stock standards were made in $8 \%$ perchloric acid to give the following concentrations: $0.005,0.01,0.05,0.1,0.5$, and $1.0 \mathrm{mmol} / 1$ chloride.

SODIUM HYDROXIDE (11 M NaOH)

Sodium hydroxide pellets (44 g) were slowly dissolved in $80 \mathrm{ml}$ of water in a beaker kept on ice. The solution was then transferred to a $100-\mathrm{ml}$ graduated flask and made up to the mark with water.

$8 \%$ PERCHLORIC ACID

$111 \mathrm{ml}$ of $72 \%$ perchloric acid were diluted to $1000 \mathrm{ml}$ with water.

\section{ELECTRODE FILLING SOLUTION}

$\left(\mathrm{Na}_{2} \mathrm{SO}_{4}, \mathrm{NH}_{4} \mathrm{Cl}\right)$

$35.5 \mathrm{~g}$ of $\mathrm{Na}_{2} \mathrm{SO}_{4}$ was dissolved in about $200 \mathrm{ml}$ of water, $5.35 \mathrm{~g}$ of $\mathrm{NH}_{4} \mathrm{Cl}$ was added, and the solution was made up to 1 litre with water. $1.0 \mathrm{ml}$ of methyl orange $(10 \mathrm{mg} / \mathrm{dl})$ was then added for easy leak detection.

ELECTRODE STORAGE SOLUTION

Same as filling solution without methyl orange.

POOLED PLASMA

Plasma from apparently normal healthy individuals was pooled and shaken repeatedly with ion-exchange resin to reduce the level of ammonia to a minimum.

\section{INSTRUMENTS}

A Technicon AutoAnalyzer AAI sampler and pump, an Orion ammonia-selective electrode (Model 9510), a Radiometer pH meter (Model PM26), and a John's scientific recorder (Model M521) were used in this study. Other apparatus used is discussed under the appropriate section in the text.

\section{Methods}

SAMPLE COLLECTION AND PRESERVATION

Specimens were collected in heparinised vacutainers, kept on ice, and taken to the laboratory as soon as possible. 1-2 ml aliquots of heparinised whole blood were then pipetted into equal amounts of chilled perchloric acid. The mixture was vortexed for 30 seconds and centrifuged at $2000 \mathrm{rpm}$ for 5 minutes. 1-2 ml aliquots of plasma can be treated similarly but plasma should be separated from cells within 15 minutes of procurement of the specimen. The supernates were then collected and assayed, as described below, or stored at $4^{\circ} \mathrm{C}$ until required.

\section{ELECTRODE ASSEMBLY AND STORAGE}

The electrode was assembled according to the procedure in the operation instruction manual with the following modifications: (a) a modified electrode? filling solution (see materials section) was use $\infty$ instead of the manufacturer's; $(b)$ only the lower of the two parafilm washers suggested by Proelss and Wright (1973) was found to be necessary to stop leakage of the internal filling solution. When not in use the electrode was disconnected from the rest of the apparatus and stored in the modified storage solution.

\section{ASSAY PROCEDURE}

The apparatus was assembled and set up as shown in Figure 1. The pH meter was set to $\mathrm{pH}$ mode and

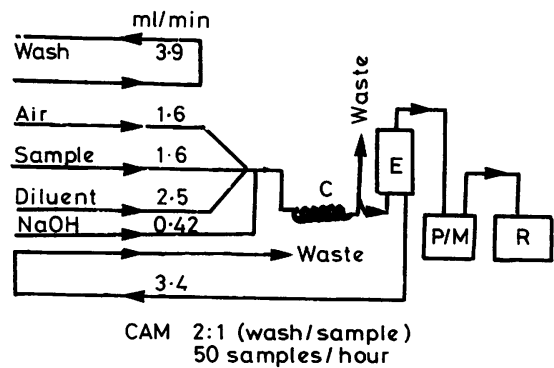

Fig. 1 Continuous-flow diagram used in the proposed method for the automated determination of ammonia in perchloric acid supernate. Concentrations are described in the Material and Methods sections. $E=$ ion-selective electrode; $P / M=p H$ meter; $C=$ single-mixing coil; $\boldsymbol{R}=$ Recorder. 
calibrated for expanded scale measurements. The recorder was then set to zero, the chart speed was set to 0.25 inch $(6 \mathrm{~mm})$ per minute, and the electrode was connected to the continuous-flow system. Diluent, followed by reagents, were run through the system until a stable baseline was achieved (5-10 minutes). The recorder pen was set to a convenient position on the chart paper for easy detection of baseline drift. Working standards and samples were then analysed according to standard automation procedures. A 1:2 (sample:wash) 50 samples per hour cam was used throughout the study. After completion of analysis, the electrode was disconnected, rinsed with electrode filling solution, and stored in the modified electrode storage solution. All lines were then washed by continuously running water through the system for 5-10 minutes.

\section{CALCUlation}

The peak heights were plotted against standard concentrations on semi-log graph paper, and the concentration of the unknown was deduced from the standard curve.

\section{CONVERSION}

$$
\begin{aligned}
0.1 \mathrm{mM} \mathrm{NH}_{4}{ }^{+} & =170 \mu \mathrm{g} / \mathrm{dl} \mathrm{NH}_{3} \\
& =140 \mu \mathrm{g} / \mathrm{dl} \mathrm{NH}_{3}-\mathrm{N}
\end{aligned}
$$

\section{REFERENCE RANGE}

In order to establish a reference range for the proposed method in our laboratory, specimens were obtained from 65 randomly selected, apparently healthy individuals. The specimens were assayed as stated in the method section, and the reference range was obtained by a cumulative frequency percent plot on a probability paper (see Fig. 5). The range obtained was $13-73 \mu \mathrm{g} / \mathrm{dl} \mathrm{NH}_{3}-\mathrm{N}$. Subjects were laboratory staff and out patients at the Grace Hospital, Windsor, Ontario, over $50 \%$ being women between the ages of 25 and 35 years. No corrections related to sex, age, or race were included in the determination.

\section{Results and discussion}

All attempts to use the electrode as a static dip type electrode for single sample analysis as stated by the manufacturer had failed. The reproducibility was poor, and leakage of the internal filling solution caused unstable electrode readings. Some success, however, was achieved with the known addition procedure (instruction manual), but the results did not compare well with the Hyland ion-exchange resin procedure (Travenol Laboratories Inc.), nor did they show satisfactory correlation with the physiological state of the patient. Owing to the absence of a true standard method for the analysis of blood or plasma ammonia, the Hyland test (an ion-exchange resin procedure) was chosen as a suitable method for comparison studies. Similar problems were encountered when the electrode was used for single sample analyses on perchloric acid supernate of plasma or whole blood (Proelss and Wright, 1973). Although the problem of leakage of internal filling solution was overcome when the electrode was assembled according to Proelss and Wright (1973), we were unable to improve the reproducibility. This then led us to investigate the incorporation of the electrode into an automated system. To accomplish

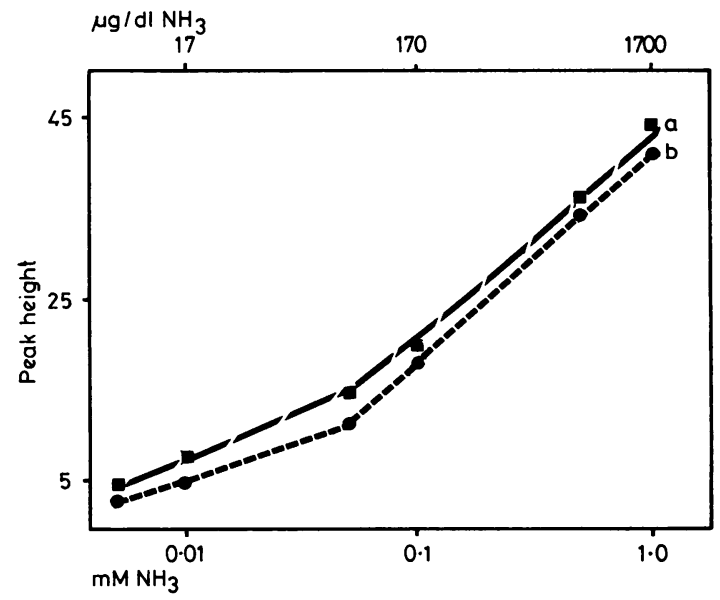

Fig. 2 Calibration curves obtained with the proposed system. ( $a$ and b) Ammonium chloride working standards made up in $0.35 \mathrm{M} \mathrm{NaCl}$ and $8 \%$ perchloric acid, respectively.

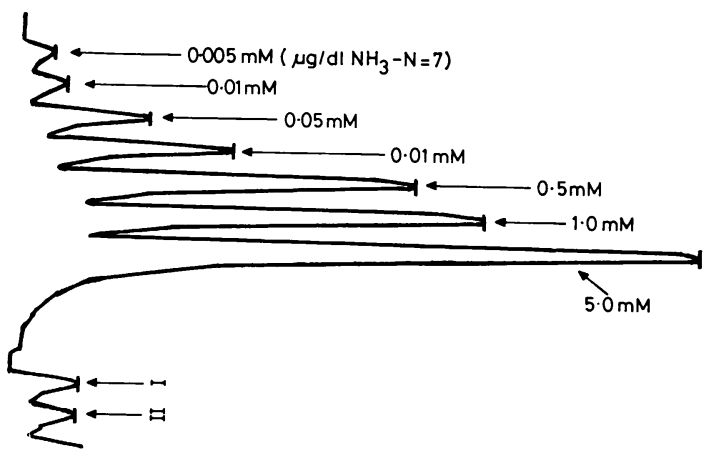

Fig. 3 AutoAnalyzer tracing obtained for the Orion ion-selective electrode as a function of increasing ammonium chloride concentrations. Working standards were prepared from a stock standard of. $0: 1 \mathrm{M} \mathrm{NH} \mathrm{H}_{4} \mathrm{Cl}$ by serial dilution in $8 \%$ perchloric acid to give the concentrations indicated on pattern. 
this, a 'flow-through' adapter was purchased from Orion. Figure 1 shows the flow diagram developed and used throughout the study, and Fig. 2 shows the standard curves obtained for ammonium chloride prepared in $8 \%$ perchloric acid and $0.35 \mathrm{M}$ $\mathrm{NaCl}$. No significant difference was observed in the slopes of the two curves. The basic shape and slope of the standard curve (bi-phasic) agree well with those obtained in the manual procedure of Proelss and Wright (1973). Apparently, this bi-phasic response is a characteristic of the electrode, and several attempts to eliminate the break-point have been unsuccessful. Figure 3 is a typical tracing obtained for the standards prepared in $8 \%$ perchloric acid. Peaks 1 and 11 represented an aqueous standard $\left(\left(\mathrm{NH}_{4}\right)_{2} \mathrm{SO}_{4}\right)$ used in the standardisation of the resin procedure.

Satisfactory correlation between the proposed method and the standard ion-exchange resin procedure was obtained. The regression line obtained was: $y=0.7 x+10$ and the correlation coefficient, r, was 0.945 (Fig. 4). These results were also in close agreement with those obtained by Park and Fenton (1973) and Proelss and Wright (1973). Within-run precision, as performed on a routine quality control serum spiked with ammonia standards (20 samples per run or batch), was well within acceptable limits $(2 \cdot 1 \%)$. Between-run precision on similar specimens was not carried out as preliminary studies (results not shown) indicated that such specimens stored at $4^{\circ} \mathrm{C}$ or $-20^{\circ} \mathrm{C}$ for one or more days yield significantly higher results. Therefore, between-run precision was determined on

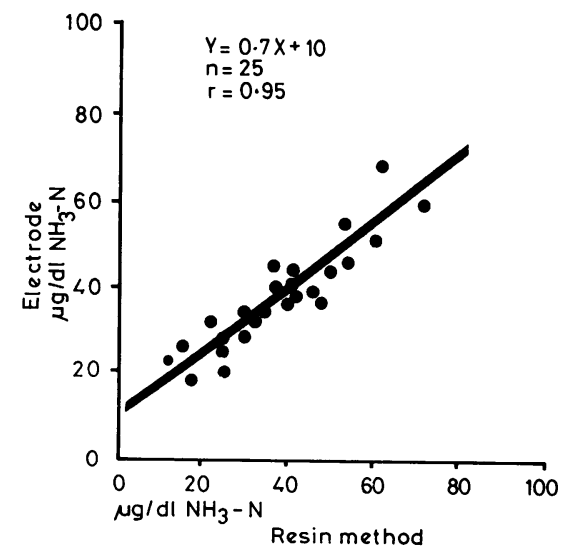

Fig. 4 Comparison studies between the proposed method and an ion-exchange resin method. Individual points on graph represent an average of duplicate assay (see Material and Methods). Both normal and abnormal specimens were used.
Table Recovery of ammonia added to pooled plasma*

\begin{tabular}{|c|c|c|c|c|}
\hline & & \multicolumn{2}{|l|}{$\mu g / d l N H_{3}-N$} & \multirow[t]{2}{*}{$\%$ Recovery } \\
\hline & & Amount added & Recovered & \\
\hline \multicolumn{2}{|c|}{ Pooled plasma } & 0 & 18 & 一 \\
\hline$"$ & ", & 22 & $21 \cdot 6$ & $98 \cdot 2$ \\
\hline ", & , & $39 \cdot 5$ & $37 \cdot 0$ & $93 \cdot 7$ \\
\hline "̈ & ", & $179 \cdot 5$ & $180 \cdot 6$ & $100 \cdot 6$ \\
\hline Mea & & - & - & $97 \cdot 5$ \\
\hline
\end{tabular}

*Ammonia in the pooled plasma was reduced to a low level by shaking with ion-exchange resin. Then $1 \cdot 0-\mathrm{ml}$ aliquots of ammonium chloride standards $(0.05,0.1,0.5 \mathrm{mmol} / \mathrm{l})$ were added to $1.0-\mathrm{ml}$ portions of pooled plasma, and equal parts of the resulting solution and $8 \%$ perchloric acid were mixed, vortexed, and centrifuged at room temperature for five minutes at $2000 \mathrm{rpm}$. The supernates were collected and assayed as stated in the Methods section. Values shown are the mean of four assays.

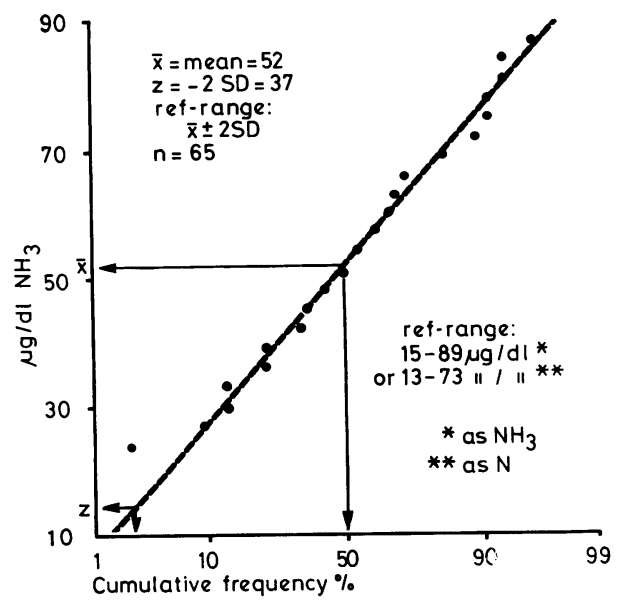

Fig. 5 Percent cumulative frequency versus amm snia concentration on probability paper. Samples obtained in a random, non-selective manner from 65 apparently healthy individuals with no history of liver disease were processed and assayed as outlined in the Methods section. Ammonia values thus obtained were plotted against percent cumulative frequency on probability paper, and a tentative reference range for the proposed method was deduced (mean $\pm 2 S D$ ).

an aqueous standard containing $140 \mu \mathrm{g} / \mathrm{dl} \mathrm{NH}_{3}-\mathrm{N}$, stored at $4{ }^{\circ} \mathrm{C}$ for two to three days. Between-run precision obtained for 16 batches was $3.5 \%$. The overall electrode precision, however, was affected by continuous usage. This was most often traced back to a membrane problem, and simply changing the membrane restored normal precision. Recovery studies carried out on pooled plasma containing three different levels of ammonia yield an average percent recovery of 97.5 (Table). A reference range of 13-73 (mean $\pm 2 \mathrm{SD}$ ) $\mu \mathrm{g} / \mathrm{dl} \mathrm{NH}_{3}-\mathrm{N}$ was calculated for the proposed method (Fig. 5). The normal range quoted by Hyland for the standard ion-exchange procedure is $5-69 \mu \mathrm{g} / \mathrm{dl} \mathrm{NH}_{3}-\mathrm{N}$. 
Previous methods using ion-selectives for the direct estimation of plasma or serum ammonia suffer from two major disadvantages: contamination of the surface of the electrode membrane by plasma proteins, and nonspecific interferences from ammonia liberated from labile amide and amino groups. The former results in a progressive lowering of the electrode response from run to run and loss of reproducibility and precision, while the latter gives falsely elevated levels for plasma ammonia. Although manual procedures, in which measurements are performed on protein-free filtrates, are not subjected to such interferences, they are tedious and often unsuitable for routine use in the clinical laboratory. In this paper we propose a simple, convenient, and inexpensive automated method for the determination of ammonia in blood. The proposed procedure is free of interferences from plasma proteins, requires minimal technologist's skill, and is suitable for routine estimation of blood ammonia in the clinical laboratory. Only minimal maintenance and relatively inexpensive equipment are required.

\section{References}

Conway, E. J., and Cooke, R. (1939). Blood ammonia. Biochemical Journal, 33, 457-478.

Dienst, S. G. (1961). An ion-exchage method for plasma ammonia concentration. Journal of Laboratory and Clinical Medicine, 58, 149-155.

Fenton, J. C. B., and Williams, A. H. (1968). Improved method for the estimation of plasma ammonia by ion-exchange. Journal of Clinical Pathology, 21, 14-18.

Forman, D. T. (1964). Rapid determination of plasma ammonia by the ion-exchange technique. Clinical Chemistry, 10, 497-508.

Hutchinson, J. H., and Labby, D. H. (1962). New method for microdetermination of blood ammonia by use of cation exchange resin. Journal of Laboratory and Clinical Medicine, 60, 170-178.

Jacobs, H. A. M., and Olthuis, F. M. F. G. (1973). A kinetic determination of ammonia in plasma. Clinica Chimica Acta, 43, 81-86.
Kingsley, G. R., and Tager, H. S. (1970). Ion-exchange method for the determination of plasma ammonia nitrogen with the Berthelot reaction. In Standard Methods of Clinical Chemistry (American Association of Clinical Chemists), Vol. 6, edited by R. MacDonald, pp. 115-126. Academic Press, New York and London.

Miller, G. E., and Rice, J. D., Jr. (1963). Determination of the concentration of ammonia nitrogen in plasma by means of a simple ion-exchange method. American Journal of Clinical Pathology, 39, 97-103.

Mondzac, A., Ehrlich, G. E., and Seegmiller, J. E. (1965). An enzymatic determination of ammonia in biological fluids. Journal of Laboratory and Clinical Medicine, 66, 526-531.

Nathan, D. G., and Rodkey, F. L. (1957). A colorimetric procedure for the determination of blood ammonia. Journal of Laboratory and Clinical Medicine, 49, 779785.

Orion Research. Ammonia Analysis in Biological Samples. Technical Note. Form \#BA/375. Orion Research Incorporated, 11 Blackstone Street, Cambridge, Mass 02139, USA.

Orion Research. Ammonia-selective Electrode Model 9510, Instruction Manual. Orion Research Incorporated, 11 Blackstone Street, Cambridge, Mass 02139, USA.

Park, N. J., and Fenton, J. C. B. (1973). A simple method for the estimation of plasma ammonia using an ion-specific electrode. Journal of Clinical Pathology, 26, 802-804.

Proelss, H. F., and Wright, B. W. (1973). Rapid determination of ammonia in a perchloric acid supernate from blood, by use of an ammonia-specific electrode. Clinical Chemistry, 19, 1162-1169.

Smith Kline Instruments Inc. (1975). Eskalab Reagent for the Determination of Blood Ammonia. Smith Kline Instruments, Incorporated, 880 West Maude, Sunnyvale, Calif. 94086, USA.

Travenol Laboratories Inc. Blood Ammonia Test. Hyland, Division of Travenol Laboratories Incorporated, Costa Mesa, Calif. 92626, USA.

Requests for reprints to: $\mathrm{Dr} \mathrm{R}$. J. Thibert, Department of Chemistry, University of Windsor, Windsor, Ontario, N9B 3P4, Canada. 